\title{
The Mandibular Nerve: The Anatomy of Nerve Injury and Entrapment
}

\author{
M. Piagkou' ${ }^{1}$, T. Demesticha², G. Piagkos ${ }^{3}$, \\ Chrysanthou Ioannis ${ }^{4}$, P. Skandalakis ${ }^{5}$ and E.O. Johnson ${ }^{6}$ \\ 1,3,4,5,6 Department of Anatomy, \\ ${ }^{2}$ Department of Anesthesiology, Metropolitan Hospital \\ Medical School, University of Athens
}

Greece

\section{Introduction}

The trigeminal nerve (TN) is a mixed cranial nerve that consists primarily of sensory neurons. It exists the brain on the lateral surface of the pons, entering the trigeminal ganglion (TGG) after a few millimeters, followed by an extensive series of divisions. Of the three major branches that emerge from the TGG, the mandibular nerve (MN) comprises the $3^{\text {rd }}$ and largest of the three divisions. The $\mathrm{MN}$ also has an additional motor component, which may run in a separate facial compartment. Thus, unlike the other two TN divisions, which convey afferent fibers, the $\mathrm{MN}$ also contains motor or efferent fibers to innervate the muscles that are attached to mandible (muscles of mastication, the mylohyoid, the anterior belly of the digastric muscle, the tensor veli palatini, and tensor tympani muscle). Most of these fibers travel directly to their target tissues. Sensory axons innervate skin on the lateral side of the head, tongue, and mucosal wall of the oral cavity. Some sensory axons enter the mandible to innervate the teeth and emerge from the mental foramen to innervate the skin of the lower jaw.

An entrapment neuropathy is a nerve lesion caused by pressure or mechanical irritation from some anatomic structures next to the nerve. This occurs frequently where the nerve passes through a fibro-osseous canal, or because of impingement by an anatomic structure (bone, muscle or a fibrous band), or because of the combined influences on the nerve entrapment between soft and hard tissues. Any mechanical injury of the nerve therefore could be considered a compression or entrapment neuropathy (Kwak et al., 2003). A usual position of TN compression is the ITF (Nayak et al., 2008), a deep retromaxillary space, situated below the middle cranial fossa of the skull, the pharynx and the mandibular ramus. The ITF contains several of the mastication muscles, the pterygoid venous plexus, the maxillary artery (MA) and the MN ramification (Prades et al., 2003) (Figure 1). The MA is in contact with the inferior alveolar nerve (IAN) and lingual nerve (LN) (Trost et al., 2009). Recently, it is believed that some cases of temporomandibular joint syndrome (TMJS), persistent idiopathic facial pain (PIFP) and myofascial pain syndrome (MPS) may be due to entrapment neuropathies of the MN in the ITF (Loughner et al., 1990). Various muscle anomalies in the ITF have been reported when considering unexplained neurological 
symptoms attributed to $\mathrm{MN}$ branches. The variations of the typical nerve course are important for adequate local anaesthesia, dental, oncological and reconstructive operations (Akita et al., 2001). Whenever observed these variations must be reported as they can cause serious implications in any surgical intervention in the region, and may lead to false neurological differential diagnosis. If anomalous $\mathrm{MN}$ branches occur in combination with the ossified ligaments, then cutaneous sensory fibres might pass through one of the foramina formed by the ossified bars (Shaw, 1993). The MN can be compressed as a result of both its course and its relation to the surrounding structures, particularly when passing between the medial pterygoid $(\mathrm{MPt})$ and lateral pterygoid $(\mathrm{LPt})$ muscles. When the pterygoid muscles contract, both the IAN and the LN may be compressed. This results in pain, particularly during chewing; and may eventually cause trigeminal neuralgia (TGN) (Anil et al., 2003). MN entrapment can lead to numbness of all peripheral regions innervated from it. It could also lead to pain during speech (Peuker et al., 2001).

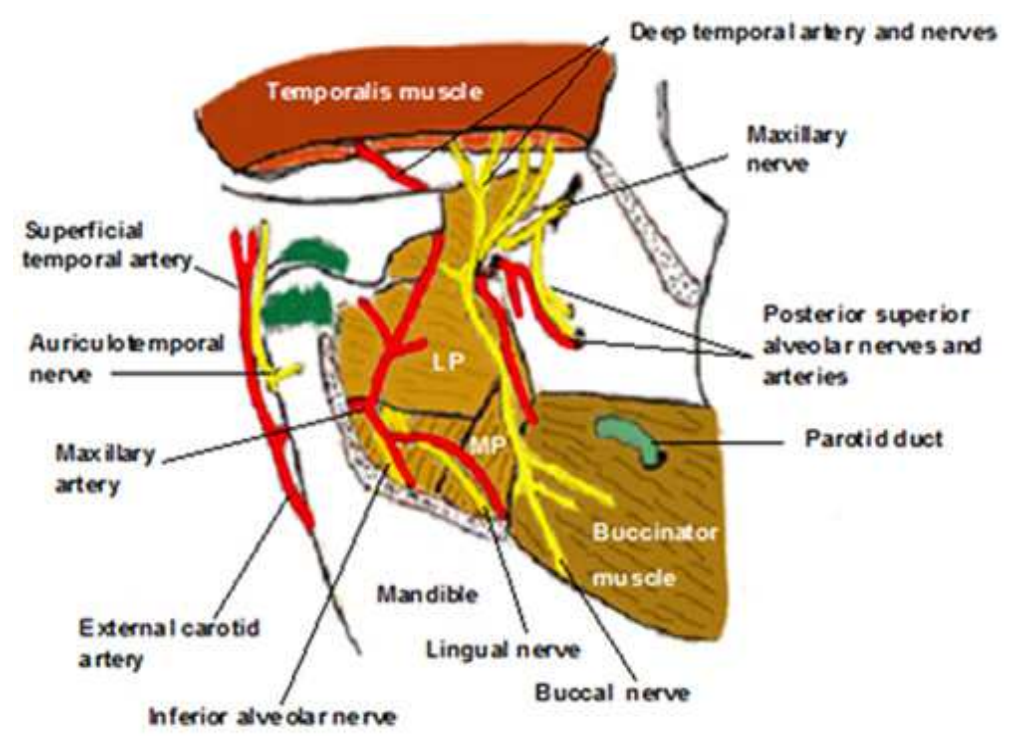

Fig. 1. The distribution of the mandibular nerve and its branches in the infratemporal fossa (ITF) 


\section{Typical course of mandibular nerve and its branches}

The MN, the largest of the three divisions of the TN, leaves the skull through the foramen ovale (FO) and enters the ITF and medial to the LPt; it divides into a smaller anterior trunk and a larger posterior trunk. The anterior trunk passes between the roof of the ITF and the $\mathrm{LPt}$ and the posterior trunk descends medially to the LPt, which might entrap the nerve (Isberg et al., 1987; Loughner et al., 1990) (Figure 2).

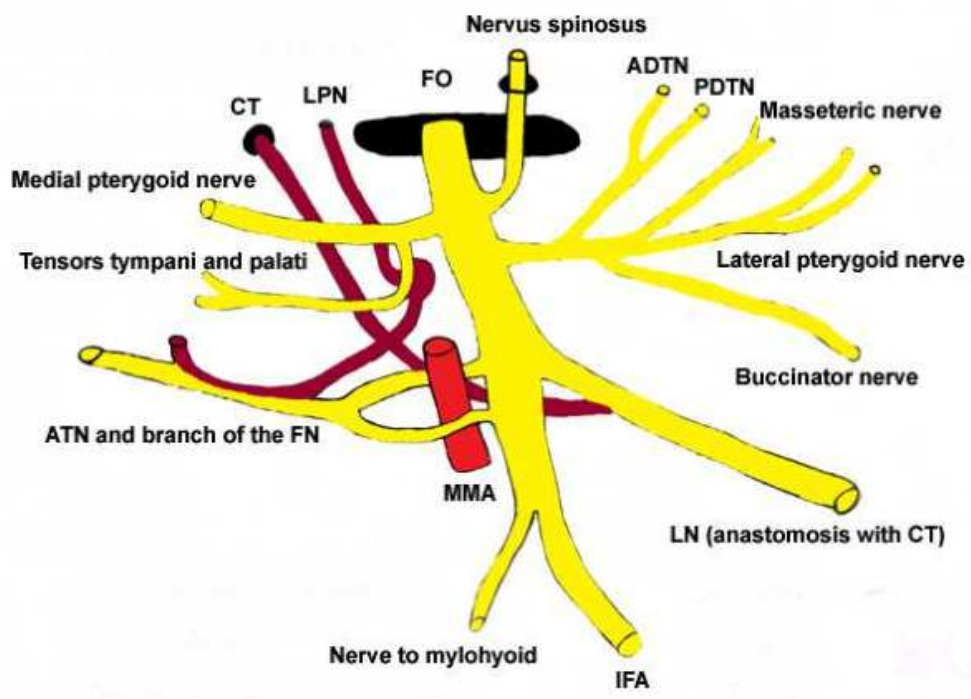

Fig. 2. The mandibular division of the TN emerging for the Foramen Ovale deep in the ITF.

\section{The anterior trunk of the MN}

The Buccal Nerve (BN) mainly supplies the LPt while passing through it and may give off the Anterior Deep Temporal Nerve (ADTN). It supplies the skin over the anterior part of the buccinator and the buccal mucous membrane, together with the posterior part of the buccal gingivae, adjacent to the $2^{\text {nd }}$ and $3^{\text {rd }}$ molar teeth. It proceeds between the two parts of the $\mathrm{LPt}$, descending deep then anteriorly to the tendon of the temporalis muscle. This normal course is a potential site of entrapment. If LPt spasm occurs, the BN could be compressed, and this compression could provoke in cheek numbness. $\mathrm{BN}$ compression has been reported by a hyperactive temporalis muscle and may result in neuralgia-like paroxysmal pain (Loughner al., 1990). Kim et al (2003) found that in 8 cadavers (33.3\%) the BN was entrapped within the anterior muscle fibres of the temporalis.

The Masseteric nerve passes laterally, above the LPt, on the skull base, anterior to the TMJ and posterior to the tendon of the temporalis; it crosses the posterior part of the mandibular coronoid notch with the masseteric artery, ramifies on, and enters the deep surface of masseter. It also supplies the TMJ. Compression of the masseteric nerve anterior to the TMJ was found in 1 joint with excessive condylar translation (Johansson et al., 1990). 
The Deep temporal nerves (DTN) usually an anterior and a posterior branch pass above the LPt to enter the deep surface of the temporalis. The small Posterior Deep Temporal Nerve (PDTN) sometimes arises in common with the masseteric nerve. The Anterior Deep Temporal Nerve (ADTN), a branch of the BN, ascends over the upper head of the LPt. A middle branch often occurs. Johannson et al. (1990) found that the DPTN may pass close to the anterior insertion of the joint capsule on the temporal bone, exposing them to the risk of mechanical irritation in condylar hypermobility. Loughner et al. (1990) observed the mylohyoid nerve and ADTN passing through the LPt. A spastic condition of the LPt may be causally related to compression of an entrapped nerve that leads to numbness, pain or both in the respective nerve distribution areas. Compression of sensory branches of the DTN by the temporalis muscle is a cause of neuropathy, (neuralgia or paresthesia) neuralgia or paresthesia (Madhavi et al., 2006).

The Nerve to the LPt enters the deep surface of the muscle and may arise separately from the anterior division or with the BN.

\section{The posterior trunk of the MN}

The Auriculotemporal Nerve (ATN) usually has 2 roots, arising from the posterior division of MN. It encircles the middle meningeal artery (MMA) and runs posteriorly passing between the sphenomandibular ligament (SML) and the neck of the mandible. It then runs laterally behind the TMJ to emerge deep in the upper part of the parotid gland. The nerve carries somatosensory and secremotor fibres of the $\mathrm{MN}$ and the glossopharyngeal nerve $(\mathrm{GPhN})$. The ATN communicates with the facial nerve $(\mathrm{FN})$ at the posterior border of the ramus where the ATN passes posterior to the neck of the condyle. If fibres cross over from the ATN to the FN and not vice versa, this communication may represent a pathway for FN sensory impairment; i.e. pain in the muscles of facial expression may occur due to an entrapped and compressed ATN. An entrapped ATN in the LPt could be the aetiology behind a painful neuropathy in a distal ATN branch supplying sensory innervation to a deranged TMJ (Akita et al., 2001).

The ATN is in close anatomic relation to the condylar process, the TMJ, the superficial temporal artery (STA) and the LPt. ATN compression by hypertrophied LPt may result in neuralgia or paresthesia of TMJ, exernal acoustic meatus and facial muscles. Further it may result in functional impairment of salivation ipsilaterally. In addition, the altered position of the ATN and its extensive or multiple loops may render the ATN more liable to entrapment neuropathy. Temple headaches occur frequently due to entrapment of ATN, which sometimes is throbbing in nature, due to its proximity to STA (Soni et al., 2009). Johannson et al. (1990) revealed the existence of topographical prerequisites for mechanical influence upon the MN branches passing in the TMJ region. In joints, with a displaced disc, the ATN trunk was almost in contact with the medial aspect of the condyle instead of exhibiting its normal sheltered course at the level of the condylar neck, thus exposing the nerve possible mechanical irritation during anteromedial condylar movements.

The Inferior alveolar Nerve (IAN) normally descends medial to the LPt. At its lower border, the nerve passes between the SML and the mandibular ramus, and then enters the mandibular canal through the mandibular foramen. In the mandibular canal it runs downwards and forwards, generally below the apices of the teeth until below the first and 
second premolars, where it divides into the terminal incisive and mental branches (Khan et al., 2009). Because the IAN is a mixed nerve, it is suggested that during development, the sensory and motor fibres are guided separately, and take different migration pathways. When the motor component of the nerve leaves for its final destination, the sensory fibres reunite (Krmpotic-Nemanic et al., 1999). It was also found that the IAN and the LN may pass close to the medial part of the condyle. In joints with this nerve topography, a medially displaced disc could interfere mechanically with these nerves. These findings could explain the sharp, shooting pain felt locally in the joint with jaw movements and the pain and other sensations projecting to the terminal area of distribution of the nerve branches near the TMJ such as the ear, temple, cheek, tongue, and teeth (Johansson et al., 1990).

The Mylohyoid Nerve branches from the IAN as the latter descends between the SML and the mandibular ramus. The mylohyoid nerve (motor nerve) passes forward in a groove to reach the mylohyoid muscle and the anterior belly of the digastric muscle. Loughner et al. (1990) found an unusual entrapment of the mylohyoid nerve in the LPt in one cadaver. Nerve compression may cause a poorly localized deep pain from the muscles it innervates. Chronic compression of the nerve results in muscular paresis. Nerve entrapment bilaterally may provoke swallowing difficulties.

The Lingual Nerve (LN) is the smallest sensory branch of the posterior trunk of the MN. Below the FO, it is united closely with the IAN. Separating from the IAN, usually 5$10 \mathrm{~mm}$ below the cranial base, it begins its course from the ITF near the otic ganglion (Kim et al., 2004). Data on LN topography in the ITF remain incomplete (Trost et al., 2009). LN runs between the tensor veli palatine and the LPt where it is joined by the chorda tympani (CT) (branch of the FN). The CT carrying taste fibres for the anterior two-thirds of the tongue and parasympathetic fibres to the submandibular and sublingual salivary glands (Zur et al., 2004). The LN emerging from the cover of the LPt, proceeds down and forwards lying on the surface of the MPt and moves progressively closer to the medial surface of the mandibular ramus until it is intimately related to the bone a few millimetres below and behind the junction of the vertical and horizontal mandible rami. Here, it lies anterior to, and slightly deeper than, the IAN. It then passes below the mandibular attachment of the superior pharyngeal constrictor and pterygomandibular raphe, closely applied to the periosteum of the medial surface of the mandible, until it lies opposite the posterior root of the $3^{\text {rd }}$ molar tooth, where it is covered only by the gingival mucoperiosteum. At the level of the upper end of the mylohyoid line, the nerve turns in a sharp curve anteriorly to continue horizontally on the superior surface of the mylohyoid muscle into the oral cavity. The LN is, at this point in close relation with to the upper pole of the submandibular gland. Farther anteriorly, the LN lies close to the posterior part of the sublingual gland and then turns medially spiraling under the submandibular duct and divides into a variable number of branches, entering the substance of the tongue. The nerve lays first on styloglossus and then on the lateral surface of the hyoglossus and genioglossus, before dividing into terminal branches which supply the overlying lingual mucosa (Peuker et al., 2001; Zur et al.,2004). In addition to receiving the $C T$ and a branch from the IAN, the LN is connected to the submandibular ganglion by two or three branches and at the anterior margin of the hyoglossus, it forms connecting loops with hypoglossal nerve twigs (Gray's 1995). The LN supplies general sensation to the mucosa, 
the floor of the mouth, the lingual gingiva and the mucosa of the anterior two thirds (presulcal part) of the tongue, being slightly overlapped posteriorly by lingual fibers of the glossopharyngeal nerve (Rusu et al., 2008). The nerve transfers neural sensory fibres for general sensitivity (pressure, temperature, pain, touch) and gustatory fibers for taste sensation to the anterior part of the tongue through the CT. The CT also carries preganglionic parasympathetic fibers providing secretomotor innervation to the submandibular, sublingual and minor salivary glands of the oral cavity (Trost et al., 2009). The medial and lateral branches bear anastomotic connections with the hypoglossal nerve in the tongue body. Knowledge of the precise anatomical distribution of the LN may aid the surgeon to ensure a safe and effective procedure (Zur et al., 2009). The LN can sometimes be entrapped, either through an ossified pterygospinous ligament, based on the outer part of the cranial base, or through an extremely wide lateral lamina of the pterygoid process of the sphenoid bone, or through the medial fibres of the lower belly of the LPt, or between the anterior margin of the pterygoid muscle and the mandibular lingual border or after its penetration in the MPt (Loughner et al., 1990; Peuker et al., 2001; Von Ludinghausen et al., 2006) (Figures 3,4). LN compression could lead to a weakening of taste transmission from the taste buds on the anterior two thirds of the tongue unilaterally (Loughner et al., 1990; Kim et al., 2004).

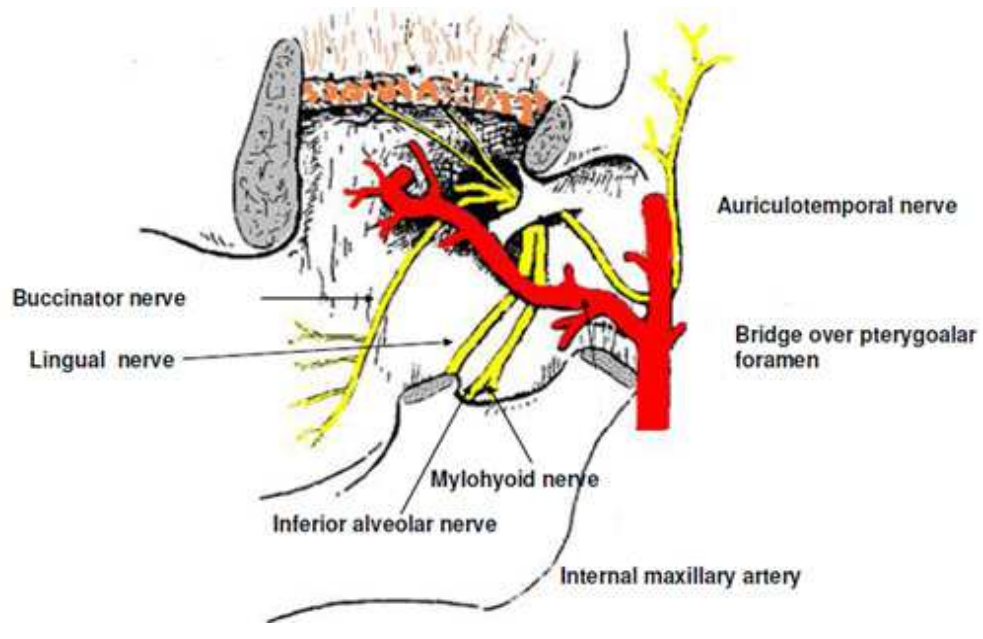

Fig. 3. The existence of pterygoalar foramen as a site of lingual nerve entrapment 


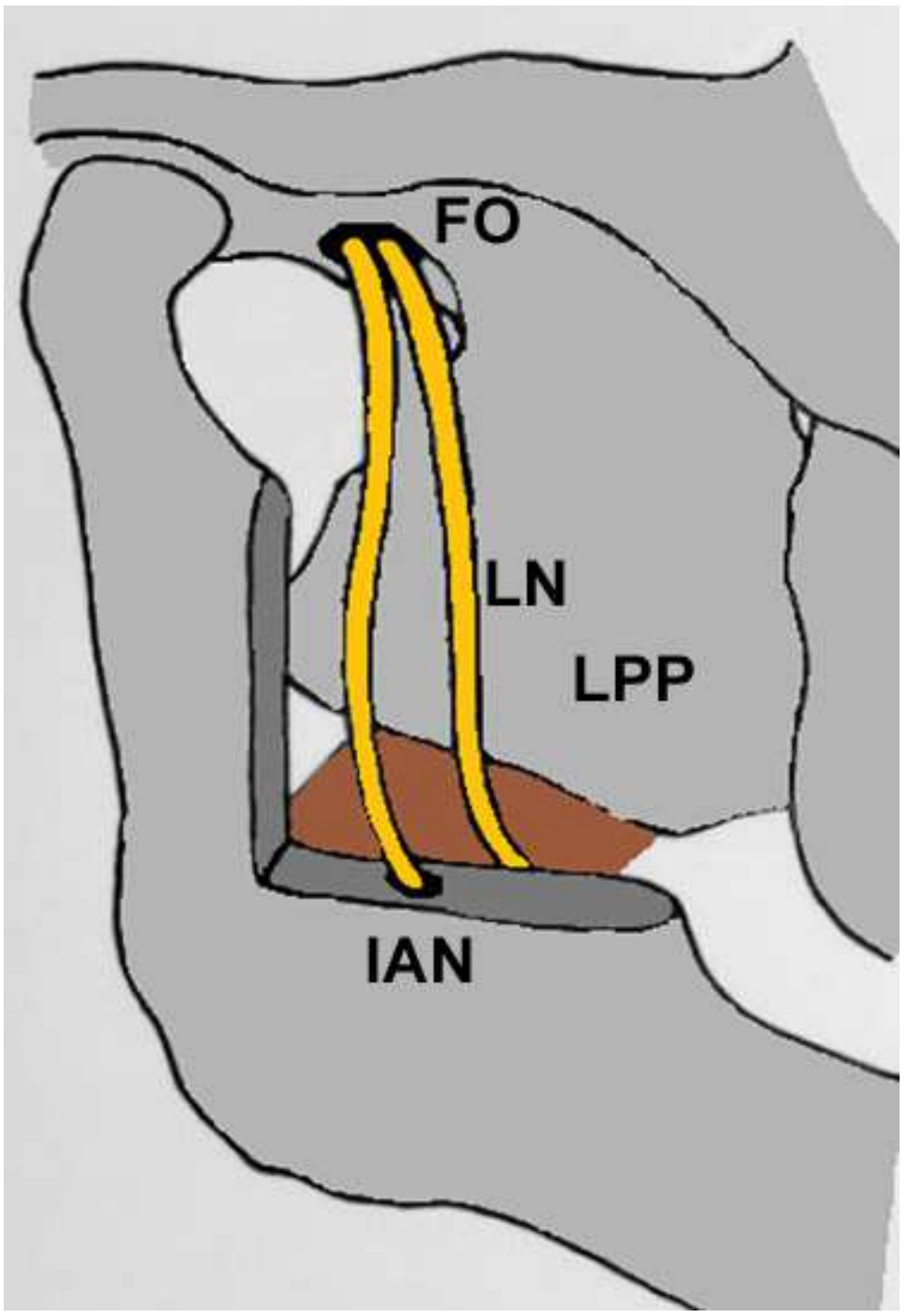

Fig. 4. A right ITF with a wide and large lateral pterygoid lamina

\section{Reaction of neurons to injury}

Reaction of neurons to physical trauma has been studied most extensively in motor neurons with peripheral axons, and centrally where their axons form well-defined tracts. When an axon is crushed or severed, changes occur on both sides of the lesion (Nauta et al., 1974; Johnson et al., 2005). Distally the axon initially swells and subsequently breaks up into a series of membrane-bound spheres. This process begins near the point of damage and progresses distally. These anterograde changes which also involve the axon 
terminal continue to total degeneration and removal of the cytoplasmic debris. Proximally, a similar series of changes may occur close to the point of injury, followed by a number of sequential, retrograde changes in the cell body (Boyd and Gordon, 2003). The process of degeneration is followed by the formation of new protein synthesizing organelles that produce distinctive proteins, destined for the regrowth of the axon (Fenrich and Gordon, 2004). Where regrowth of the axon is possible, the presence of an intact endoneurial sheath near to and beyond the region of injury is important if the axon is to reestablish satisfactory contact with its previous end organ or a closely adjacent one. The myelin sheath distal to the point of injury degenerates and is accompanied by mitotic proliferation of the Schwann cells, which fill the space inside the basal lamina of the old endoneurial tube (Quarles, 2002). Where a gap is present between the severed ends of the nerve, proliferating Schwann cells emerge from the stumps and form a series of nucleated cellular cords which bridge the interval (Fenrich and Gordon,2004). This may persist for a long time even in the absence of satisfactory nerve regeneration. Successful sprouts enter the proximal end of the endoneurial tube and grow distally in close contact with the surfaces of the Schwann cells it contains. This involves a process of contact guidance between the tip of the axon and the Schwann cell surfaces in the endoneurial tube and when present those which form Bungners bands. When the axon tip has reached and successfully reinnervated an end organ, the surrounding Schwann cells commence to synthesize myelin sheaths. Before full functional regeneration can occur, a considerable period of growth of both axonal diameter and myelin sheath thickness is necessary. This occurs when a high number of effective peripheral connections have been established. Regeneration of central axons does not normally occur, perhaps because of the absence of definite endoneurial tubes (Fenrich and Gordon, 2004). In general, when an axon is cut, Wallerian degeneration leads to axon degeneration and loss of conduction by 4 days. As a result of interruption of the post-ganglionic sympathetic efferent fibers, vaso- and sudomotor paralysis is observed, resulting in red and dry skin in the area innervated by the nerve (Johnson et al., 2005). Various progressive changes take place in the target organs, skin blood vessels and sensory receptors. Peripherally, the muscle target losses its function, and centrally, motor neurons undergo atrophy and are often lost. One to 3 days after an axon is cut, the tips of the proximal stump forms growth cones that send out exploratory pseudopodia. Motor axonal regeneration is compromised by chronic distal nerve stump denervation, induced by delayed repair or prolonged regeneration distance, suggesting that the pathway for regeneration is progressively impaired with time and distance. Poor functional recovery after peripheral nerve injury has been generally attributed to inability of deneravated muscles to accept reinnervation and recover from denervation atrophy. On the other hand, deterioration of the environment produced by Schwann cells may play a more vital role. For the most part, atrophic Schwann cells retain their capacity to remyelinate regenerated axons, although they may loose their capacity to support axonal regeneration when chronically denervated. The importance of axonal regeneration through Schwann cell tubes surrounded by a basal lamina in the distal stump explains, in part, the different degrees of regeneration that are seen after crush injuries compared to transection. Although axons may be severed in crush injury, the Schwann cells, basal lamina and perineurium maintain continuity and, thus, facilitate regeneration. Considerable debate remains concerning the extent of axonal damage following chronic compression of axons (Johnson et al., 2005). 


\section{Mechanisms of entrapment neuropathies}

Compression neuropathies are highly prevalent, debilitating conditions with variable functional recovery following surgical decompression. Chronic nerve compression induces concurrent Schwann cell proliferation and apoptosis in the early stages, without morphological and electrophysiological evidence of axonal damage. Proliferating Schwann cells down regulate myelin proteins, leading to local demyelination and remyelination in the region of injury. Axonal sprouting is related to the down regulation of myelin proteins, such as myelin-associated glycoprotein. This is contrast to acute crush or transection injuries, which are characterized by axonal injury followed by Wallerian degeneration (Pham and Gupta, 2009).

The posterior trunk of the MN might be entrapped occasionally from ligament's ossification between the lateral pterygoid process and the sphenoid spine near the FO (Isberg et al., 1987; Loughner et al., 1990; Kapur et al., 2000).

Although specific information regarding the clinical significance of ossified ligaments near the FO is limited, ossified ligaments appear to be very important from a practical clinical standpoint in relation to the different methods of block anesthesia of the MN (Lepp and Sandner, 1968). Additionally, these occasional structures may be important by producing various neurological disturbances (Shaw, 1993). Krmpotic-Nemanic et al. (2001) noted that a pterygospinous foramen replacing the FO could provoke trigeminal neuralgia (Figure 5).

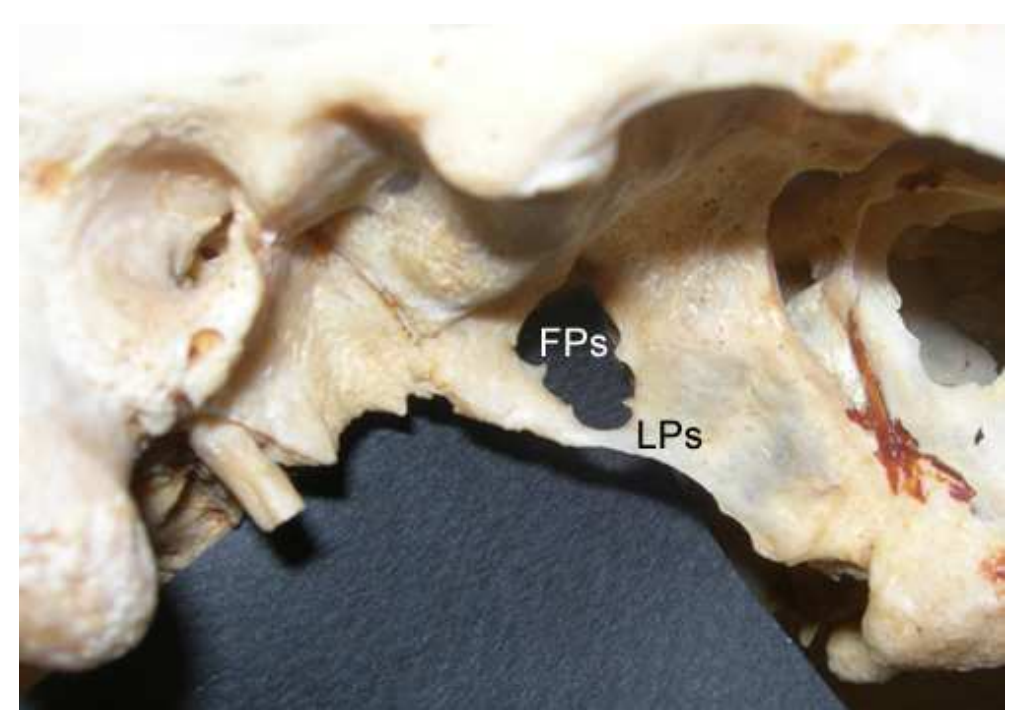

Fig. 5. Complete pterygospinous osseous bar and the enlarged pterygospinous foramen on the left side of a Greek dry skull 


\section{The injury of the lingual nerve (LN)}

Injury to peripheral branches of the (TN) is a known sequelae of oral and maxillofacial surgical procedures. The two prime mechanisms of LN injury included crushing and transection. Although crush injuries are considered less severe than transection injuries, the axon distal to the injury site in both cases degenerates (Sunderland, 1951). However, unlike transection injuries, the connective tissue elements remain in continuity after crushing, which provides guidance for axonal sprouts from the regenerating central stump (Sunderland, 1951; Johnson et al., 2005). Injury to the LN is associated with changes in the epithelium of the tongue, particularly in the differentiation of the papillae and taste buds. Structural studies around the site of the injury show an apparent increase in the number of fascicles distal the crush site, suggesting considerable damage to the perineurium (Holland et al., 1996). The number of nonmyelinated axons distal to site of injury is double after crush injuries compared to control counts. This suggests that axonal sprouting persists for at least 12 weeks, with a rapid restoration of near-normal fibers for good functional recovery (Holland et al., 1996). Centrally, the principle change proximal to the nerve crush site is a loss of small-diameter myelinated axons from the chorda tympani. In addition, there is also an increase in the number of non-myelinated axons proximal to the crush site, indicative of continued sprouting following degeneration.

\section{The entrapment of the lingual nerve (LN)}

LN compression causes numbness, hypoesthesia, dysaesthesia, paraesthesia, or even anesthesia in all innervated regions. The patient may also present with dysgeusia, difficulty in chewing and loss of gustatory function on the side of the compression. Numbness of one lateral half or of the tip of the tongue can affect speech articulation of the frontal lingual consonants (Isberg et al., 1987; Antonopoulou et al., 2008). The LN can be entrapped, either through an ossified pterygospinous or pterygoalar ligament, based on the outer part of the cranial base, or through an extremely wide lateral lamina of the pterygoid process of the sphenoid bone, or through the medial fibers of the lower belly of the LPt (Sunderland, 1991) (Figures 4, 6,7,8). Recently, it is believed that, some cases of TMJ syndrome or myofascial pain syndrome could be a result of nerve entrapment in the ITF (Kopell and Thompson, 1976; Von Ludinghausen et al., 2006). A usual position of LN compression is the ITF contains the muscles of mastication, the pterygoid venous plexus, the MA and the ramification of the MN. The presence of a partially or completely ossified pterygospinous or pterygoalar ligament can obstruct the passage of a needle into the FO and disable the anesthesia of the trigeminal ganglion or the MN for relief of trigeminal neuralgia (Lepp and Sandner, 1968; Skrzat et al., 2005) (Figures 5,6,7,8). The presence of ossified LPs may compress the surrounding neurovascular structures causing lingual numbness and pain associated with speech impairment (Peuker et al., 2001; Das and Paul, 2007). Considering the close relationship of the CT, it may also be compressed by the anomalous bone bar and thus, result in abnormal taste sensation in the anterior two thirds of the tongue. The lateral lamina of the pterygoid process and the median pterygoid muscle forms the medial wall of the ITF. Elongation of the lateral lamina could result in weakening of the MPt and paresthesia of the buccal region (Skrzat et al., 2006). In cases of extremely large lateral laminae, the LN and IAN in the ITF are forced to take a longer more curved course, to follow the shape of the enlarged lamina. As a result, during contraction of the pterygoid 
muscles, both nerves can be compressed (Figure 4). The lateral pterygoid plate is an important landmark for mandibular anesthesia and a wide lateral pterygoid plate may confuse anesthetists or surgeons exploring the para- and retro-pharyngeal space (Kapur et al., 2000; Das and Paul, 2007).

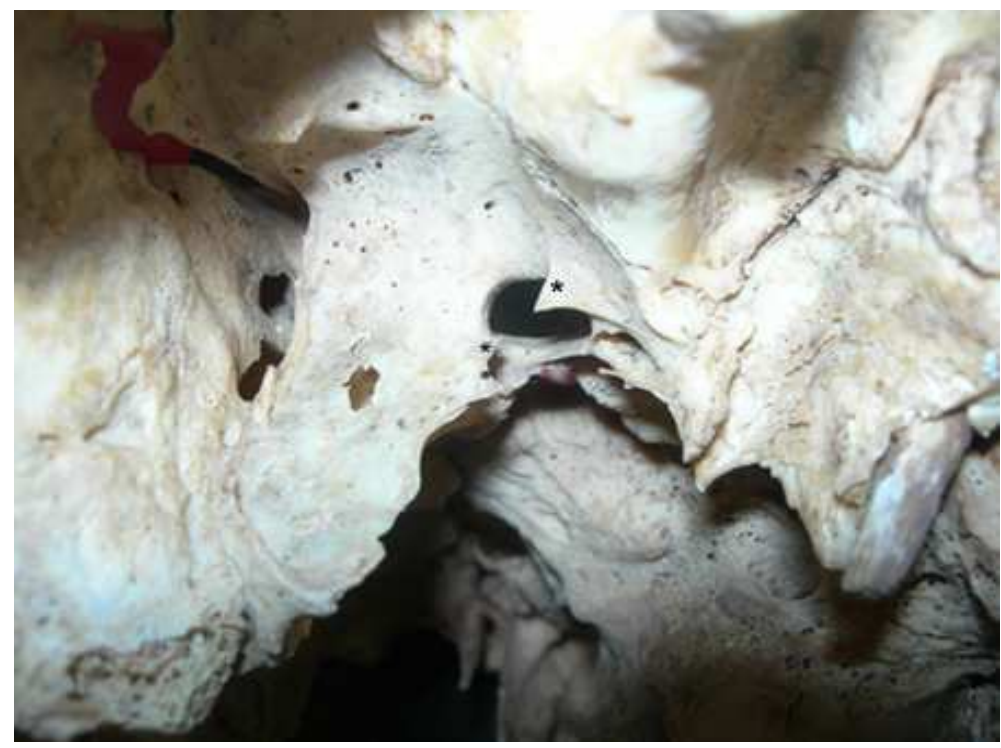

Fig. 6. Incomplete pterygospinous foramen on the left side of a Greek dry skull

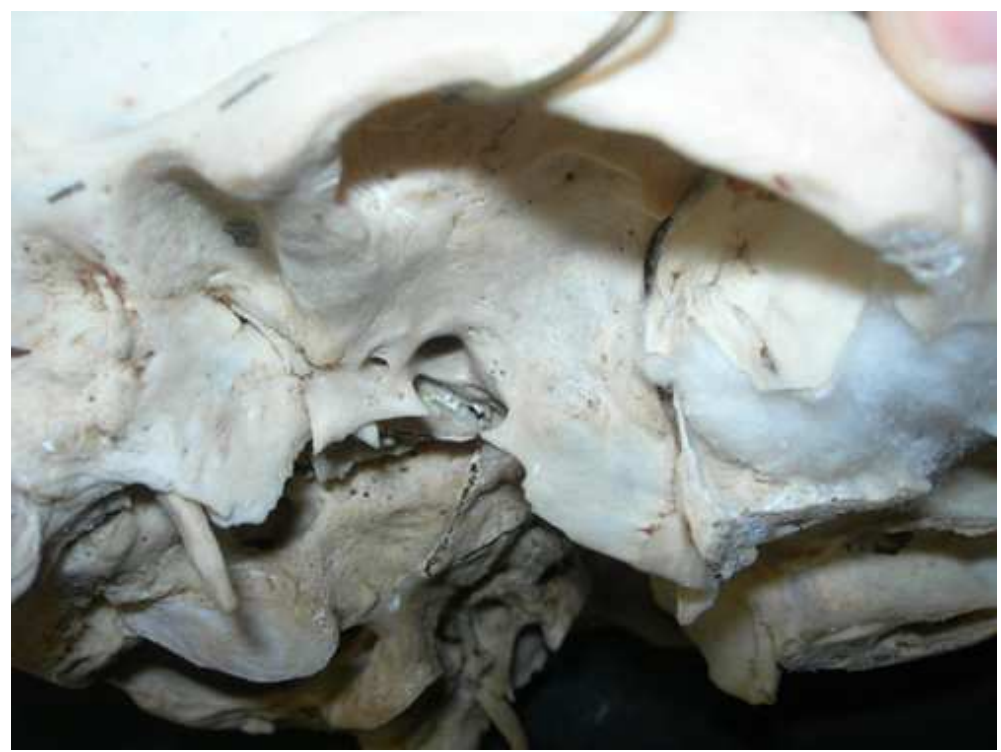

Fig. 7. Incomplete pterygoalar bar on the right side of a Greek dry skull 


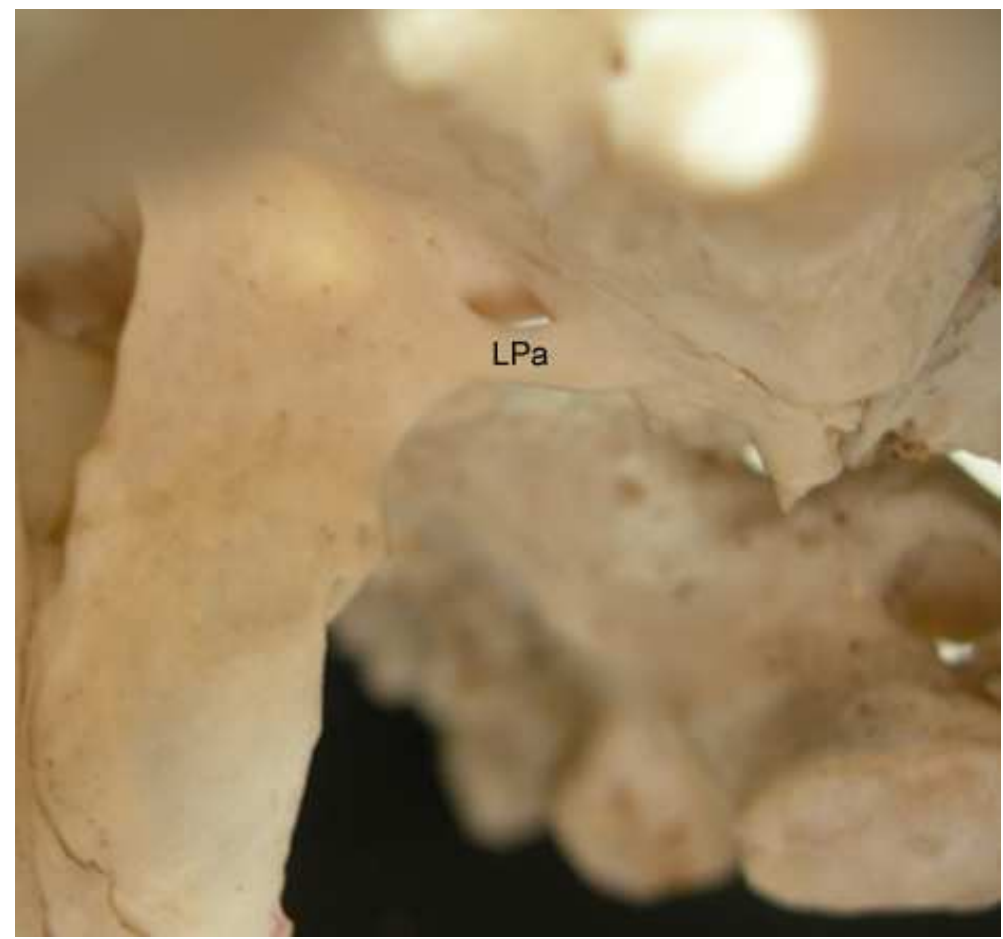

Fig. 8. Complete pterygoalar bar and a pterygoalar foramen on the left side of a Greek dry skull

LN entrapment can potentially occur between the median pterygoid bundles, or in the inferior head of the lateral pterygoid muscle, indicating that LPt spasm could cause LN compression and result in tongue numbness, anesthesia, or paresthesia at the tip of the tongue and speech articulation problems.

\section{The entrapment of the remaining branches of the $\mathrm{MN}$ posterior trunk}

An entrapped auriculotemporal nerve (ATN) in the lateral pterygoid muscle (LPt) could be the etiology behind a painful neuropathy in a distal ATN branch supplying sensory innervation to a deranged TMJ (Akita et al., 2001). The ATN is in close anatomic relation to the condylar process, the TMJ, the superficial temporal artery and the LPt. ATN compression by the hypertrophied LPt may result in neuralgia or paresthesia of TMJ, external acoustic meatus and facial muscles. Further it may result in functional impairment of salivation ipsilaterally. In addition, the altered position of the ATN and its extensive or multiple loops may render the ATN more liable to entrapment neuropathy. Temple headaches occur frequently due to entrapment of ATN, which sometimes is throbbing in nature, due to its proximity to superficial temporal artery (Soni et al., 2009). In joints, with a displaced disc, the ATN trunk can be almost in contact with the medial aspect of the condyle (Johansson et al., 1990). Thus, instead of exhibiting its normal sheltered course at the level of the condylar neck, the nerve is exposed to possible mechanical irritation during 
anteromedial condylar movements. Topographically, the IAN may pass close to the medial part of the condyle. As such, a medially displaced disc could interfere mechanically with this nerve. This could explain the sharp, shooting pain felt locally in the joint with jaw movements as well as the pain and other sensations projecting to the terminal area of distribution of the nerve branches near the TMJ, such as the ear, temple, cheek, tongue, and teeth (Johansson et al., 1990).

An unusual entrapment of the mylohyoid nerve in the LPt may cause a poorly localized deep pain from the muscles it innervates. Chronic compression of the nerve results in muscular paresis. This symptom would be subclinical unless the nerve entrapment is bilateral; then swallowing difficulties may ensue (Loughner et al., 1990).

\section{Conclusions}

Entrapment neuropathies are specific forms of compressive neuropathies occurring when nerves are confined to narrow anatomic passageways including soft and/or hard tissues making them susceptible to constricting pressures. Chronic nerve compression alters the normal anatomical and functional integrity of the nerve. Dentists and oral maxillofacial surgeons should be very suspicious of possible signs of neurovascular compression in the region of the ITF.

\section{References}

Akita K, Shimokawa T, Sato T. 2000. Positional relationships between the masticatory muscles and their innervating nerves with special reference to the lateral pterygoid and the midmedial and discotemporal muscle bundles of temporalis. J Anat 197: 291-302.

Akita K, Shimokawa T, Sato T. 2001. Aberrant muscle between the Temporalis and the Lateral Pterygoid Muscles: M. pterygoideus proprius (Henle). Clin Anat 14: 288291.

Anil A, Peker T, Turgut HB, Gulekon IN, Liman F. 2003. Variations in the anatomy of the inferior alveolar nerve. British Journal of Oral and Maxillofacial Surgery 41: 236239.

Antonopoulou M, Piagkou M, Anagnostopoulou S. 2008. An anatomical study of the pterygospinous and pterygoalar bars and foramina- their clinical relevance. Journal of Cranio-Maxillofacial Surgery 36: 104-108.

Boyd JG, Gordon T. 2003. Neurotrophic factors and their receptors in axonal regeneration and functional recovery after peripheral nerve injury. Mol Neurobiol 27:277-324.

Das S, Paul S. 2007. Ossified pterygospinous ligament and its clinical implications. Bratisl Lek Listy 108:141-143.

De Froe, Wagennar JH. 1935. Die Bedeutung des porus crotaphitico-buccinatorius and des Foramen pterygospinosum fur Neurologic and Rontgenologic

Fenrich K, Gordon T. 2004. Canadian Association of Neuroscience review: Axonal regeneration in the peripheral and central nervous systems-current issues and advances. Can J Neurol Sci 31:142-156.

Gray's Anatomy. 1995. Churchill Livingstone, New York, 28 th edition, p. 380-381. 
Holland GR, Robinson PP, Smith KG, Pehowich E. 1996. A quantitative morphological study of the recovery of cat lingual nerves after transection or crushing. J Anat 188:289297.

Isberg AM, Isacsson G, Williams WN, Loughner BA. 1987. Lingual numbness and speech articulation deviation associated with temporomandibular joint disk displacement. Oral Surg Oral Med Oral Pathol 64: 9-14.

Johansson AS, Isberg A, Isacsson G. 1990. A radiographic and histologic study of the topographic relations in the temporomandibular joint region: implications for a nerve entrapment mechanism. J Oral Maxillofac Surg 48: 953-961.

Johnson EO, Zoubos AB, Soucacos PN. 2005. Regeneration and repair of peripheral nerves. Injury 36 Suppl 4:S24-S29.

Kapur E, Dilberovic F, Redzepagic S, Berhamovic E. 2000. Variation in the lateral plate of the pterygoid process and the lateral subzygomatic approach to the mandibular nerve. Med Arh 54: 133-137.

Khan MM, Darwish HH, Zaher WA. 2009. Perforation of the inferior alveolar nerve by the maxillary artery: An anatomical study. British Journal of Oral and Maxillofacial Surgery (in Press)

Kim HJ, Kwak HH, Hu KS, Park HD, Kang HC, Jung HS, Koh KS. 2003. Topographic anatomy of the mandibular nerve branches distributed on the two heads of the lateral pterygoid. Int J. Oral Maxillofac. Surg 32: 408-413.

Kim SY, Hu KS, Chung IH, Lee EW, Kim HJ. 2004. Topographic anatomy of the lingual nerve and variations in communication pattern of the mandibular nerve branches. Surg Radiol Anat 26: 128-135.

Kopell HP, Thompson WAL. 1976. Peripheral Entrapment Neuropathies. Huntington, New York: Krieger Publishing Company. p 1-7.

Krmpotic - Nemanic J, Vinter J, Jalsovec D. 2001. Accessory oval foramen. Ann Anat 183: 293-295

Krmpotic-Nemanic J, Vinter I, Hat J, Jalsovec D. 1999. Mandibular neuralgia due to anatomical variations. Eur Arch Otorh 256: 205-208

Kwak HH, Ko SJ, Jung HS, Park HD, Chung IH, Kim HJ. 2003. Topographic anatomy of the deep temporal nerves, with references to the superior head of lateral pterygoid. Surg Radiol Anat 25: 393-399

Lang J. 1995. Skull base and related structures - Atlas of Clinical Anatomy. Stuttgart, Schattauer; p. 55-57, 300-311

Lang J, Hetterich A. 1983. Contribution on the postnatal development of the processus pterygoideus. Anat Anz 154: 1-31

Lepp FH, Sandner O. 1968. Anatomic-radiographic study of ossi.ed pterygospinous and 'innominate' ligaments. Oral Surg Oral Med Oral Pathol 26:244-260.

Loughner BA, Larkin LH, Mahan PE. 1990. Nerve entrapment in the lateral pterygoid muscle. Oral Surg Oral Med Oral Pathol 69:299-306.

Madhavi C, Issac B, Jacob TM. 2006. Variation of the middle deep temporal nerve: A case report. Eur J Anat 10: 157-160

Nauta HJ, Pritz MB, Lasek RJ. 1974. Afferents to the rat caudoputamen studied with horseradish peroxidase: An evaluation of retrograde neuroanatomical research methods. Brain Res 67:219- 238. 
Nayak SR, Rai R, Krishnamurthy A, Prabhu LV, Ranade AV, Mansur DI, Kumar S. 2008. An unusual course and entrapment of the lingual nerve in the infratemporal fossa. Bratisl Lek Listy 109: 525-527

Nayak SR, Saralaya V, Prabhu LV, Pai MM, Vadgaonkar R, D’ Costa S. 2007. Pterygospinous bar and foramina in Indian skulls: incidence and phylogenetic significance. Surg Radiol Anat 29: 5-7

Newton TH, Potts DG (1971) Radiology of the skull and brain. Vol.1. St Louis: I. Mosby, p. 307

Ozdogmus O, Saka E, Tulay C, Gurdal E, Uzun I, Cavdar S (2003) The anatomy of the carotico-clinoid foramen and its relation with the internal carotid artery. Surg Radiol Anat 25: 241-246

Patnaik VVG, Singla Rajan K, Bala Sanju (2001) Bilateral pterygoalar bar and porus crotaphitico-buccinatorius- a case report. J Anat. Soc. India 50: 161-162

Peker T, Karakose M, Anil A, Turgut H.B, Gulekon N (2002) The incidence of basal sphenoid bony bridges in dried crania and cadavers: Their anthropological and clinical relevance. Eur J Morphol 40: 171-80

Peuker ET, Fischer G, Filler TJ. 2001. Entrapment of the lingual nerve due to an ossified pterygospinous ligament. Clin Anat 14:282-284.

Pham K, Gupta R. 2009. Understanding the mechanisms of entrapment neuropathies. Review article. Neurosurg Focus 26:E7.

Piagkou M, Demesticha T, Piagkos G, Androutsos G, Skandalakis P. 2011. Mandibular nerve entrapment in the infratemporal fossa. Surg Radiol Anat 33: 291-299.

Piagkou M, Demesticha T, Piagkos G, Androutsos G, Skandalakis P. 2010. Lingual nerve entrapment in muscular and osseous structures. IJOS 2 (4): 181-189.

Pinar Y, Arsu G, Aktan Ikiz za, Bilge O (2004) Pterygospinous and pterygoalar bridges. Sendrom 16; 66-69

Prades JM, Timishenko A, Merzougui N (2003) A cadaveric study of a combined transmandibular and trans-zygomatic approach to the infratemporal fossa. Surg Radiol Anat 25: 180-187

Quarles RH. 2002. Myelin sheaths: Glycoproteins involved in their formation, maintenance and degeneration. Cell Mol Life Sci 59:1851-1871.

Rusu MC, Nimigean V, Podoleanu L, Ivascu RV, Niculescu MC. 2008. Details of the intralingual topography and morphology of the lingual nerve. Int J Oral Maxillofac Surg 37:835-839.

Sakamoto Y, Akita K. 2004. Spatial relationships between masticatory muscles and their innervating nerves in man with special reference to the medial pterygoid muscle and its accessory muscle bundle. Surg Radiol Anat 26:122-127

Shaw JP. 1993. Pterygospinous and pterygoalar foramina: A Role in the etiology of Trigeminal Neuralgia? Clin Anat 6: 173-178

Shaw JP. 1993. Pterygospinous and pterygoalar foramina: A role in the etiology of trigeminal neuralgia? Clin Anat 6:173-178.

Shimokawa T, Akita K, Sato T, Ru F, Yi SQ, Tanaka S. 2004. Penetration of muscles by branches of the mandibular nerve: A possible cause of neuropathy. Clin Anat 17:25 . 
Shimokawa T, Akita K, Soma K, Sato T. 1998. Innervation analysis of the small muscle bundles attached to the temporalis: truly new muscles or merely derivatives of the temporalis? Surg Radiol Anat 20: 329-334

Skrzat J, Walocha J, Srodek R. 2005. An anatomical study of the pterygoalar bar and the pterygoalar foramen. Folia Morphol 64: 92-96

Skrzat J, Walocha J, Srodek R, Nizankowska A. 2006. An atypical position of the foramen ovale. Folia Morphol 65:396-399.

Skrzat J,Walocha J, Srodek R. 2005. An anatomical study of the pterygoalar bar and the pterygoalar foramen. Folia Morphol 64:92-96.

Soni S, Rath G, Suri R, Vollala VR (2009) Unusual organization of Auriculotemporal Nerve and Its Clinical Implications. Journal of Oral and Maxillofacial Surgery 67: 448-450

Sunderland S (1991) Nerve injuries and their repair: a critical appraisal. Churchill Livingstone, New York, p. 129-146

Sunderland S. 1951. A classification of peripheral nerve injuries producing loss of function. Brain 74:491-516.

Sutherland S (1978) Nerves and nerve injuries. New York: Churchill Livingstone, p. 343-350

Tebo HG (1968) The pterygospinous bar in panoramic roentgenography. Oral Surg Oral Med Oral Pathol 26: 654-657

Trost O, Kazemi A, Cheynel N, Benkhadra M, Soichot P, Malka G, Trouilloud P (2009) Spatial relatioships between linbgual nerve and mandibular ramus: original study method, clinical and educational applications. Surg Radiol Anat 31: 447-452

Tubbs RS, May WR Jr, Apaydin N, Shoja MM, Shokouhi G, Loukas M, Cohen-Gadol AA. 2009. Ossification of ligaments near the foramen ovale: An anatomic study with potential clinical significance regarding transcutaenous approaches to the skull base. Neurosurgery 65(6 Suppl):60-64.

Von Ludinghausen M, Kageyama I, Miura M, Al Khatib M (2006) Morphological pecularities on the deep infratemporal fossa in advanced age. Surg Radiol Anat 28: 284-292

Yoshimasu F, Kurland LT, Elveback LR (1972) Tic douloureux in Rochester, Minnesota, 1945-1969. Neurology, 22: 952-956

Zakrzewska JM (1990) Medical management of trigeminal neuralgia. Br Dent J 168: 399-401

Zur KB, Mu L, Sanders I. 2004. Distribution pattern of the human lingual nerve. Clin Anat 17:88-92. 


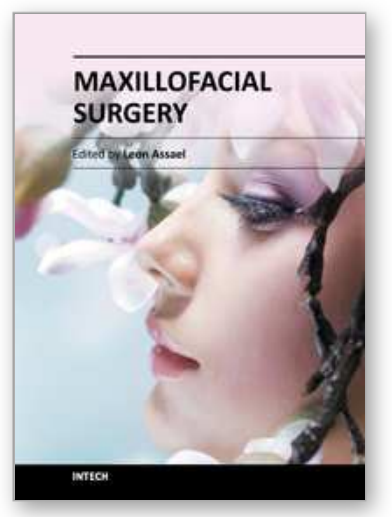

\author{
Maxillofacial Surgery \\ Edited by Prof. Leon Assael
}

ISBN 978-953-51-0627-2

Hard cover, 86 pages

Publisher InTech

Published online 23, May, 2012

Published in print edition May, 2012

\title{
How to reference
}

In order to correctly reference this scholarly work, feel free to copy and paste the following:

M. Piagkou, T. Demesticha, G. Piagkos, Chrysanthou loannis, P. Skandalakis and E.O. Johnson (2012). The Mandibular Nerve: The Anatomy of Nerve Injury and Entrapment, Maxillofacial Surgery, Prof. Leon Assael (Ed.), ISBN: 978-953-51-0627-2, InTech, Available from: http://www.intechopen.com/books/maxillofacialsurgery/the-mandibular-nerve-the-anatomy-of-nerve-injury-and-entrapment

\section{INTECH}

open science | open minds

\section{InTech Europe}

University Campus STeP Ri

Slavka Krautzeka 83/A

51000 Rijeka, Croatia

Phone: +385 (51) 770447

Fax: +385 (51) 686166

www.intechopen.com

\section{InTech China}

Unit 405, Office Block, Hotel Equatorial Shanghai

No.65, Yan An Road (West), Shanghai, 200040, China 中国上海市延安西路65号上海国际贵都大饭店办公楼405单元

Phone: +86-21-62489820

Fax: +86-21-62489821 
(C) 2012 The Author(s). Licensee IntechOpen. This is an open access article distributed under the terms of the Creative Commons Attribution 3.0 License, which permits unrestricted use, distribution, and reproduction in any medium, provided the original work is properly cited. 